\title{
There's been a flaw in our thinking
}

\section{Clark L. Anderson*}

Division of Immunology, Department of Internal Medicine, The Ohio State University, Columbus, OH, USA

*Correspondence: anderson.48@osu.edu

Edited by:

Jan Terje Andersen, Oslo University Hospital, Norway

Reviewed by:

Inger Øynebråten, Oslo University Hospital and University of Oslo, Norway

Keywords: FcRn, IgG, transport, albumin, turnover rate

Rogers Brambell (1901-1970), the father of the field of FcRn biology, was by all accounts a scientist of great imagination and insight, one whom we would look to, were he available, for opinions on our current scientific direction. Were we to ask him, in a moment of fantasy, to review recent progress in his field, we think he would say that we have gone astray, that we have become confused about what he thought was a critical issue. Specifically, we have ignored the important point of where in the cell FcRn expresses its specificity for ligand, either on or in the cell; and rather than deal directly with that basic issue, we have side-stepped the question, leaving it unanswered, and in fact have implied that it is not a critical question.

His last comment on the issue, in his 1970 tome, published the year he died, was that specificity of the receptor for ligand in tissues like the yolk sac was determined intracellularly in what we now know to be acidic vesicles of the pinocytic trafficking pathway. Thus receptor-bound ligand destined for transcellular transport was separated effectively from free ligand destined for lysosomal degradation. To others, however, the situation seemed more complex, and alternate views were expressed. In the gut of the neonatal rat or mouse, the receptor was found expressed on the epithelial surface where under the influence of the low $\mathrm{pH}$ of gut contents it bound with high affinity to the IgG in maternal milk, and both the receptor and its bound ligand were endocytosed, the ligand ultimately reaching its destination, the fetal circulation. Receptor specificity for ligand, thus, was conferred at the cell surface.

For receptor-ligand specificity to be dictated at two different sites depending on the nature of the tissue seemed far-fetched to some, and additional observations were brought to bear. The low $\mathrm{pH}$ of gut contents was questioned. Gut $\mathrm{pH}$ had been measured only once, with litmus paper, and the observation was never repeated. As well, the relevance of surface-expressed receptor was questioned. It became apparent that only a fraction of total cell receptor, probably $<1 \%$, is found on the surface of the cell. This low level of surface expression is likely a vestige of the exocytosis step of IgG transport and not an essential component of the ligand-uptake pathway. Further, an experiment expressly designed to evaluate the effect of gut $\mathrm{pH}$ on IgG transfer to the neonate indicated that acidic $\mathrm{pH}$ was not necessary; nonspecific uptake of ligand into the cell was adequate (1).

Despite underlying doubts about the physiologic relevance of surface-displayed receptor, it proved virtually impossible to perform in vitro studies of IgG uptake by cultured cells unless the medium was made acidic. Uptake at physiologic $\mathrm{pH}$ was near nil. Thus, workers proceeded to exploit IgG uptake at low $\mathrm{pH}$ by surface receptors in attempts to understand the subsequent steps in $\operatorname{IgG}$ endocytosis. A handful of strategies were used. Some experiments were performed with adherent cells such as the Madin-Darby Canine Kidney cells wherein IgG transport was followed after uptake in pH6 medium [e.g., Ref. (2)]. More recently, both IgG and FcRn have been mutated to manifest high affinity for one another at physiological $\mathrm{pH}$, so that uptake of IgG by the surface receptors of these cells can be studied at physiological $\mathrm{pH}$ without resorting to a low-pH uptake step [e.g., Ref. (3)]. In the neonatal rat, gut IgG trafficking has been followed after instillation of $\mathrm{pH} 6$ ligand into the gut lumen [e.g., Ref. (4)].

The last two decades have witnessed a spate of studies describing the intracellular trafficking that follows ligand uptake by surface receptors [14 papers from multiple laboratories in 18 years; see citations in Ref. (5)]. By ignoring alternative pathways, these studies appear to assume that this pathway is the major if not the only uptake pathway. They seem to ignore the possibility that this surface-receptor-initiated pathway may be different and distinct from a pathway that ensues after ligand binding to the receptor in the acidic endosome subsequent to non-specific pinocytosis of ligand. The latter pathway, first hypothesized by Brambell in his original formulation, has not yet been studied in vitro in isolated cells. Yet, this pathway is almost certainly the one utilized in the IgG degradation pathway and in the yolk sac transport pathway. And, there are solid reasons to believe that it is the pathway used for transport across the neonatal gut in mice and rats.

So, what accounts for ignoring this pathway for two decades, the pathway that begins with non-specific uptake of ligand and receptor recognition of ligand in acidic endosomes? Why has attention been directed solely at the pathway following ligand binding to surface-expressed receptor? The literature is not helpful in answering why a more direct approach has not been taken, why it has not been possible to learn how acidic endosomes take up $\operatorname{IgG}$ that has been non-specifically endocytosed and how FcRn then moves its ligand across the cell. Perhaps, it is enough for an essay of this sort, one person's opinion, to point out that we workers in the field have passed over an important question, and the whole story of 
FcRn transport will not be readily understood unless we return to basic experiments and answer these fundamental questions. I invite my colleagues to respond to this challenge.

\section{REFERENCES}

1. Benlounes N, Chedid R, Thuillier F, Desjeux JF, Rousselet F, Heyman M. Intestinal transport and processing of immunoglobulin $\mathrm{G}$ in the neonatal and adult rat. Biol Neonate (1995) 67:254-63. doi: $10.1159 / 000244173$

2. Tzaban S, Massol RH, Yen E, Hamman W, Frank SR, Lapierre LA, et al. The recycling and transcytotic pathways for IgG transport by $\mathrm{FcRn}$ are distinct and display an inherent polarity. J Cell Biol (2009) 185:673-84. doi:10.1083/jcb.200809122
3. Prabhat P, Gan Z, Chao J, Ram S, Vaccaro C, Gibbons $\mathrm{S}$, et al. Elucidation of intracellular recycling pathways leading to exocytosis of the Fc receptor, FcRn, by using multifocal plane microscopy. Proc. Natl. Acad. Sci. U.S.A. (2007) 104:5889-94. doi:10.1073/pnas.0700337104

4. Ladinsky MS, Huey-Tubman KE, Bjorkman PJ. Electron tomography of late stages of FcRnmediated antibody transcytosis in neonatal rat small intestine. Mol Biol Cell (2012) 23:2537-45. doi:10. 1091/mbc.E12-02-0093

5. Mohanty S, Kim J, Ganesan LP, Phillips GS, Robinson JM, Anderson CL. Abundant intracellular IgG in enterocytes and endoderm lacking FcRn. PLoS One (2013) 8:e70863. doi:10.1371/journal.pone. 0070863

Conflict of Interest Statement: The author declares that the research was conducted in the absence of any commercial or financial relationships that could be construed as a potential conflict of interest.

Received: 14 August 2014; accepted: 12 October 2014; published online: 31 October 2014.

Citation: Anderson CL (2014) There's been a flaw in our thinking. Front. Immunol. 5:540. doi: 10.3389/fimmu.2014.00540

This article was submitted to Immunotherapies and Vaccines, a section of the journal Frontiers in Immunology. Copyright (C) 2014 Anderson. This is an open-access article distributed under the terms of the Creative Commons Attribution License (CC BY). The use, distribution or reproduction in other forums is permitted, provided the original author(s) or licensor are credited and that the original publication in this journal is cited, in accordance with accepted academic practice. No use, distribution or reproduction is permitted which does not comply with these terms. 